\title{
Interactions Between Frankliniella fusca and Pantoea ananatis in the Center Rot Epidemic of Onion (Allium cepa)
}

\author{
Bhabesh Dutta, Ronald Gitaitis, Apurba Barman, Utku Avci, Kathleen Marasigan, and Rajagopalbabu Srinivasan
}

First and second authors: Department of Plant Pathology, University of Georgia, Tifton 31793; third, fifth, and sixth authors: Department of Entomology, University of Georgia, Tifton 31793; and fourth author: Complex Carbohydrate Research Center, University of Georgia, Athens 30602.

Accepted for publication 26 April 2016.

\begin{abstract}
Dutta, B., Gitaitis, R., Barman, A., Avci, U., Marasigan, K., and Srinivasan, R. 2016. Interactions between Frankliniella fusca and Pantoea ananatis in the center rot epidemic of onion (Allium cepa). Phytopathology 106:956-962.

An Enterobacteriaceae bacterium, Pantoea ananatis (Serrano) Mergaert, is the causal agent of an economically important disease of onion, center rot. $P$. ananatis is transmitted by an onion-infesting thrips, Frankliniella fusca (Hinds). However, interactions between $F$. fusca and $P$. ananatis as well as transmission mechanisms largely remain uncharacterized. This study investigated $P$. ananatis acquisition by thrips and transstadial persistence. Furthermore, the effects of bacterial acquisition on thrips fitness were also evaluated. When thrips larvae and adults were provided with acquisition access periods (AAP) on peanut leaflets contaminated with the

bacterium, an exponentially positive relationship was observed between AAP and $P$. ananatis acquisition $\left(R^{2} \geq 0.77, P=0.01\right)$. $P$. ananatis persisted in thrips through several life stages (larvae, pupae, and adult). Despite the bacterial persistence, no significant effects on thrips fitness parameters such as fecundity and development were observed. Immunofluorescence microscopy of adult thrips with $P$. ananatis-specific antibody after $48 \mathrm{~h}$ AAP on contaminated food revealed that the bacterium was localized only in the gut. These results suggested that the pathogen is not circulative and could be transmitted through feces. Mechanical inoculation of onion seedlings with fecal rinsates produced center rot symptoms, whereas inoculation with rinsates potentially containing salivary secretions did not. These results provide evidence for stercorarian transmission (transmission through feces) of $P$. ananatis by $F$. fusca.
\end{abstract}

A number of Enterobacteriaceae members are phytopathogenic, and infections of these bacteria cause diseases in agricultural crops of economic importance (Bell et al. 2007; Bruton et al. 2003; Gitaitis and Gay 1997; Medrano and Bell 2007; Mitchell and Hanks 2009; Schwartz and Otto 2000). Examples include center rot of onion, bacterial wilt in cucumber, and yellow vine of cucurbits caused by Pantoea ananatis (Serrano) Mergaert, Erwinia tracheiphila (Smith), and Serratia marcescens Bizio, respectively (Bruton et al. 2003; Gitaitis and Gay 1997; Mitchell and Hanks 2009). Insects serve as vectors of several phytopathogenic Enterobacteriaceae members (Bell et al. 2007; Bruton et al. 2003; Gitaitis and Gay 1997; Medrano and Bell 2007; Mitchell and Hanks 2009). However, details on effects of enterobacteria on vector preference and fitness are limited when compared with transmission of other bacterial pathogens such as Xylella fastidiosa (Wells et al.), 'Candidatus Liberibacter asiaticus' (Jagoueix et al.), and viruses (Almeida et al. 2005; Daugherty and Almeida 2009; Hill and Purcell 1995; Nachappa et al. 2012). In the majority of such interactions, the intricacy of vector-pathogen interactions seems to largely influence vector preference and fitness (Mauck et al. 2012). The effects of phyotpathogenic enterobacteria on vectors' preference and fitness remain uninvestigated.

In this study, an attempt was made to further characterize interactions of enterobacteria with their arthropod vectors using the onion center rot pathosystem as a model. Center rot is one of the important bacterial diseases of onion, which affects onion production in the United States (Gitaitis and Gay 1997; Gitaitis et al. 2002, 2003). The symptoms of center rot include white streaks with water soaked margins running the length of the leaf and eventual soft rotting

Corresponding author: B. Dutta; E-mail address: bhabesh@uga.edu of bulbs. Under favorable conditions, this disease has the potential to cause $100 \%$ yield loss (Gitaitis et al. 2002, 2003). Though P. ananatis could be seedborne (Walcott et al. 2002), it is widely believed that the primary mode of $P$. ananatis transmission to onion in the southern United States is by an insect vector tobacco thrips (Frankliniella fusca (Hinds)) (Gitaitis et al. 2003; Wells et al. 2002). F. fusca is also the most prevalent thrips species on onion plants in the southern United States (Diffe et al. 2008; Sparks et al. 2011).

Gitaitis et al. (2003) indicated that onion-colonizing thrips such as $F$. fusca could transmit $P$. ananatis but did not elucidate the interactions between thrips and $P$. ananatis. In general, details on interactions between phytopathogenic Enterobacteriaceae members and their vectors from an anatomical and physiological standpoint are, as yet, unclear. Particularly, details on pathogen localization or infection of insect tissues, persistence within the insect, and effects on vector fitness are not known. It is also not clear whether bacteria are transmitted to a susceptible host through feeding by salivary secretions or through other means such as regurgitation following biofilm formation and proventirculus blockage, as in the case of an animal-infecting Enterobacteriaceae member, Yersinia pestis (Jarrett et al. 2004). Very few studies have examined plant-infecting enterobacteria localization in arthropod vectors. Dutta et al. (2014) demonstrated that $P$. ananatis was localized only in the gut of its thrips vector, Thrips tabaci (Lindeman). Nevertheless, it is unknown whether the localization pattern of $P$. ananatis is conserved among thrips vectors.

The goals of this study were to gather basic information pertaining to acquisition of $P$. ananatis by its thrips vector ( F. fusca) and examine persistence in thrips. An additional goal was to assess whether persistence of $P$. ananatis has any effect on the fitness of its vector. Experiments to assess the acquisition efficiency of $P$. ananatis by $F$. fusca adults and larvae and persistence of $P$. ananatis in $F$. fusca were conducted. To evaluate the effects of $P$. ananatis infection on $F$. fusca fitness, microcosms (Plexiglas cages) were used to monitor 
the development of $F$. fusca for an entire generation (adult to adult). Immunofluorescent labeling with $P$. ananatis-specific antibodies was used to localize $P$. ananatis in thrips. Subsequently, membrane feeding assays and inoculation assays were conducted to investigate the mechanism of $P$. ananatis transmission by $F$. fusca. A previously optimized peanut leaf assay was used to study the acquisition and persistence of $P$. ananatis by $F$. fusca (Gitaitis et al. 2003; Wells et al. 2002).

\section{MATERIALS AND METHODS}

Bacterial strains and inoculum preparation. $P$. ananatis strain PNA 97-1 isolated from symptomatic onion foliage showing center rot symptoms was used in this study (Gitaitis and Gay 1997). Inoculum preparation was done by inoculating $3 \mathrm{ml}$ of nutrient broth with single colonies of bacterial strain from a 48-h-old culture on nutrient agar (NA). The inoculated nutrient broth was incubated overnight at $28^{\circ} \mathrm{C}$ on a rotary shaker (Innova; New Brunswick Scientific) at $150 \mathrm{rpm}$. After incubation, $3 \mathrm{ml}$ of bacterial suspension was centrifuged at 6,000 $\times g$ (Allegra 25R; Beckman Coulter) for $5 \mathrm{~min}$. The supernatant was discarded and the pellet was resuspended in $1 \mathrm{ml}$ of $0.1 \mathrm{M}$ phosphate-buffered saline solution (PBS) $(0.01 \mathrm{M}$ $\mathrm{KHPO}_{4}-\mathrm{K}_{2} \mathrm{HPO}_{4}, \mathrm{pH} 7.0$, and $0.75 \% \mathrm{NaCl}$ ). The bacterial concentration was adjusted to an optical density of 0.3 at $600 \mathrm{~nm}$ (approximately $1 \times 10^{8} \mathrm{CFU} / \mathrm{ml}$ ) using a spectrophotometer (Spectronic 20; Bausch and Lomb), and 10-fold serial dilutions were prepared in $0.9 \mathrm{ml}$ of PBS to obtain desired concentrations of $1 \times 10^{6}$ CFU/ ml. Confirmation of bacterial populations was checked by dilution plating of a $0.1-\mathrm{ml}$ aliquot on NA.

F. fusca maintenance. A colony of $F$. fusca was established in 2009 on noninfected 'Georgia Green' peanut leaflets with thrips collected from peanut blooms from the Belflower Farm, University of Georgia, Tifton. Since then, thrips were maintained in Munger cages (Munger 1942) on peanut (Georgia Green) leaflets. Munger cages were maintained in a growth chamber (Thermo Scientific) at 25 to $30^{\circ} \mathrm{C}$ with a photoperiod of $14 \mathrm{~h}$ of light and $10 \mathrm{~h}$ of darkness per $24 \mathrm{~h}$. In order to confirm whether the peanut plants were negative for $P$. ananatis, leaflets $(n=5)$ without surface sterilization were rinsed in $2 \mathrm{ml}$ of $0.1 \mathrm{M}$ PBS for $2 \mathrm{~min}$. The aliquots of $0.1 \mathrm{ml}$ were then spread-plated on PA-20 semiselective medium (Goszczynska et al. 2006) and incubated. Thrips in the colony were also crushed and spread-plated on PA-20 medium to check for $P$. ananatis contamination. The majority ( $>90 \%$ ) of individuals in the colonies were females. Adult females were subsequently used for all experiments.

Surface sterilization of peanut leaflets and $\boldsymbol{F}$. fusca larvae and adults. Peanut leaflets $(n=15)$ were collected from thrips-free plants maintained in the greenhouse, which were surface sterilized using $10 \%$ sodium hypochlorite for $30 \mathrm{~s}$ and transferred to $70 \%$ ethanol for an additional $30 \mathrm{~s}$. After rinsing twice in $2 \mathrm{ml}$ of $0.1 \mathrm{M}$ PBS, leaflets were placed in individual petri plates with partially opened lids and air dried in a laminar airflow chamber for 15 to $20 \mathrm{~min}$. After drying, individual leaflets were placed in separate 2-ml microcentrifuge tubes. The efficiency of surface sterilization was assessed by spread plating $0.1-\mathrm{ml}$ rinsates of five individual leaflets from the last rinsing step in replicates $(n=3)$ on PA-20 plates and incubating for 6 days at $28^{\circ} \mathrm{C}$.

For surface sterilization of thrips, individuals were randomly collected from the laboratory-maintained colony and surface sterilized using the same procedure as described above. Rinsates from three replicates (from the last rinsing step with PBS) of 10 thrips were assessed separately by spread plating $0.1-\mathrm{ml}$ aliquots on PA-20 plates followed by incubation for 6 days at $28^{\circ} \mathrm{C}$. Additionally, the confirmation of laboratory-reared thrips (adult and larvae) being devoid of $P$. ananatis populations in their gut was achieved by macerating three replicates of 10 surface-sterilized thrips (adult and larvae) separately in $1.5-\mathrm{ml}$ microcentrifuge tubes. The macerates were then suspended in $1 \mathrm{ml}$ of $0.1 \mathrm{M}$ PBS followed by spread plating of 0.1-ml aliquots on PA-20 agar plates. Upon incubation at $28^{\circ} \mathrm{C}$ for 6 days, plates were assessed for $P$. ananatis bacterial colonies.

Confirmatory tests for $\boldsymbol{P}$. ananatis. Bacterial colonies were characterized by the presence of yellow colonies ( 3 to $4 \mathrm{~mm}$ in diameter) with dark inclusion body on PA-20 (Goszczynska et al. 2006), gram reaction, utilization of glucose in oxidative and fermentative reaction, indole reaction, and nitrate reductase reaction. In addition, real-time polymerase chain reaction (PCR) specific for $P$. ananatis was also conducted on three random colonies per agar plate. For PCR, a single bacterial colony was suspended in $25 \mu \mathrm{l}$ of sterile deionized water and heated (Modular Dry Block Heaters) for 3 min at $95^{\circ} \mathrm{C}$. DNA extract $(5 \mu \mathrm{l})$ was amplified using a commercial real-time PCR mastermix (Bio-Rad iQ Supermix; Bio-Rad) in a $25-\mu$ reaction with $25 \mu \mathrm{M}$ each primer PanITS1 (5'-GTCTGAT AGAAAGATAAAGAC-3') and EC5 (5'-CGGTGGATG CCCTG GCA-3') (Walcott et al. 2002) and $10 \mu \mathrm{M}$ TaqMan probe 6-FAM AGCGGTTAGGACTCCGCCCTTTCA-BHQ. The real-time PCR was carried out in a Cepheid Smart Cycler using the following thermal profile: denaturation at $95^{\circ} \mathrm{C}$ for $180 \mathrm{~s}$, and 35 cycles each of denaturation at $95^{\circ} \mathrm{C}$ for $15 \mathrm{~s}$ and annealing at $60^{\circ} \mathrm{C}$ for $40 \mathrm{~s}$. Samples with cycle threshold values less than 35 were considered positive for $P$. ananatis.

Acquisition of $P$. ananatis by $\boldsymbol{F}$. fusca adults and larvae. After air drying, peanut leaflets $(n=15)$ were placed in a $2-\mathrm{ml}$ microcentrifuge tube containing $1 \mathrm{ml}$ of $P$. ananatis at $1 \times 10^{6}$ $\mathrm{CFU} / \mathrm{ml}$. Leaflets were incubated for $5 \mathrm{~min}$ and air dried for 2 to $3 \mathrm{~min}$. Two to three surface-sterilized peanut leaflets (dipped in a bacterial suspension of $1 \times 10^{6} \mathrm{CFU} / \mathrm{ml}$ ) were placed inside Munger cells $(11.5$ by $9 \mathrm{~cm}$ ) lined with a moistened filter paper (Whatman number 2). Peanut leaflets incubated in PBS and air dried in Munger cells served as negative controls. Five cells were used for each treatment and PBS control. Fifty adults and larvae of $F$. fusca were released per Munger cell, and the percentage of thrips acquiring bacteria was assessed in a time-course study. At each acquisition access period (AAP) $(0,1,6,24$, and $48 \mathrm{~h})$, four individual adults and larvae of $F$. fusca were randomly sampled from each Munger cell and placed into separate $1.5-\mathrm{ml}$ microcentrifuge tubes. After surface sterilization, the collected thrips (adult and larvae) were assayed individually for the presence of bacteria using dilution plating on PA-20 medium. Surface sterilization rinsate (from the last rinsing step with PBS) was also tested for the presence of $P$. ananatis by plating. Thrips fed on PBS-inoculated leaves served as a negative control. Percentages of $P$. ananatis-positive thrips (adult and larvae) at different AAP were recorded. This experiment was repeated five more times, with four replicates per treatment per time point. Regression analysis was used to determine the relationship between AAP and percentage of thrips (adult and larvae) acquiring $P$. ananatis. Regression analysis was conducted using PROC REG in SAS (version 9.1; SAS Institute) after assessing for differences among experiments using PROC GENMOD in SAS.

Transstadial persistence of $\boldsymbol{P}$. ananatis in $\boldsymbol{F}$. fusca. For this experiment, second-instar $F$. fusca larvae that developed from a cohort of eggs were exposed to $P$. ananatis-contaminated peanut leaflets. Surface-disinfested peanut leaflets $(n=15)$ were inoculated (leaflets dipped in bacterial suspension of $1 \times 10^{6} \mathrm{CFU} / \mathrm{ml}$ ) with $P$. ananatis and placed in Munger cells. Fifty noninfected larvae of $F$. fusca, reared on $P$. ananatis-free peanut leaflets, were released per Munger cell and were given an AAP of $48 \mathrm{~h}$. After incubation, larvae were removed and transferred to a separate Munger cell with surface-disinfested peanut leaflets, which served as a clean source of food. The surface-disinfested leaflets were replaced every alternate day. Samples of four individuals were randomly selected and surface sterilized from each Munger cell at $6 \mathrm{~h}$ postexposure at the pupal stage ( $96 \mathrm{~h}$ postexposure) and the adult stage (144 h postexposure). Samples collected were placed into separate $1.5-\mathrm{ml}$ microcentrifuge tubes. Surface sterilization rinsates (from the last rinsing step with PBS) were also plated and evaluated to ensure no $P$. ananatis surface contamination in thrips. Presence of 
$P$. ananatis from individual thrips was assayed separately by macerating and plating on PA-20 medium, as described above. After a period of incubation, percentages of $P$. ananatis-positive thrips at each sampling period were recorded. This experiment was repeated five more times, with four replicates per treatment per time point.

Effect of $\boldsymbol{P}$. ananatis acquisition on $\boldsymbol{F}$. fusca fitness. Time taken to complete an entire generation (adult to adult) and adult development were monitored on surface-sterilized peanut leaflets with and without epiphytic populations of $P$. ananatis. Peanut leaflets were placed in separate Munger cages and 10 thrips were released in each cage. Ten cages were set up (five for thrips with $P$. ananatis-contaminated leaflets and five for thrips with peanut leaflets without $P$. ananatis), and the experiment was repeated two more times $(n=300$ thrips on leaflets with and without $P$. ananatis populations). Munger cages were kept in a growth chamber (Thermo Scientific) at 25 to $30^{\circ} \mathrm{C}$ with a 14 -h photoperiod. Leaflets with or without $P$. ananatis in Munger cages were replaced every alternate day. The released adult thrips were removed from cages 5 days later, the cages were monitored daily under a compound microscope (Meiji Techno), and newly hatched larvae were recorded. The number of adults emerging from each cage was recorded at 24-h intervals, and the adults were removed. Observations were recorded until there were no more larvae or adults in each cage. Differences in the number of adults produced were estimated by subjecting the data to linear mixed models using PROC GLIMMIX. Treatments were considered as fixed effects and replications were considered as random effects. The median development time required for the first adult to develop was estimated for thrips on leaflets with and without $P$. ananatis populations. Statistical significance of differences in development time on leaflets with and without $P$. ananatis was estimated by a Wilcoxon Rank Sum test with a continuity correction factor of 0.5 and a Kruskal-Wallis test.

Immunolocalization of $P$. ananatis in adult $F$. fusca. Adult F. fusca $(n=10)$ were allowed to feed on peanut leaflets dipped in a suspension containing $P$. ananatis at $1 \times 10^{6} \mathrm{CFU} / \mathrm{ml}$ for $48 \mathrm{~h}$ and sampled for immunofluorescence microscopy. Thrips $(n=$ 10) fed on PBS-treated peanut leaflets served as negative controls. Thrips samples were fixed, washed (buffer and sterile water), and dehydrated using an ascending ethanol series (Dutta et al. 2014). The dehydrated tissues were gradually infiltrated with LR White embedding resin (Ted Pella Inc.) and transferred to gelatin capsules containing fresh $100 \%$ LR White resin (Electron Microscopy Sciences) for polymerization. Longitudinal sections $(250 \mathrm{~nm})$ of thrips were made using a Leica EM UC6 ultra-microtome (Leica Microsystems) and mounted on glass slides. Two sections per sample were stained with $0.05 \%$ Toluidine blue to visualize the basic cellular arrangement. The remaining sections were immunolabeled with polyclonal rabbit anti-PNA (primary) (Walcott et al. 2002) and Alexa Fluor 488 conjugated goat antirabbit (secondary). Sections were observed using a fluorescence microscope (Nikon Eclipse 80i) with filter (wavelength 450 to $650 \mathrm{~nm}$ ) attached to a Nikon DS-Ril camera, and bacterial localization in thrips was documented.

Transmission of $\boldsymbol{P}$. ananatis to onion seedlings through F. fusca salivary and fecal rinsates obtained through membrane feeding. Laboratory-maintained thrips (negative for $P$. ananatis) in three subsets ( $n=15 /$ subset) were allowed to feed on peanut leaflets dipped in a suspension containing $P$. ananatis at $1 \times 10^{6} \mathrm{CFU} / \mathrm{ml}$ for $72 \mathrm{~h}$. Later, thrips were surface sterilized and transferred to sterile 1.5-ml microcentrifuge tubes. The opening of each tube was sealed with stretched paraffin film (Parafilm; American Can Company) to facilitate thrips probing and feeding. A drop (50 $\mu \mathrm{l})$ of sucrose solution $(7 \% \mathrm{wt} / \mathrm{vol})$ was placed on top of the paraffin film. A second layer of paraffin film, stretched likewise, was placed at the top of the first layer. Two to three holes were made on the paraffin film (on both layers) for aeration using a fine entomological pin (Indigo Instruments). The paraffin layers were removed after 3 days of incubation and thrips were extracted. Thrips feces were collected by thoroughly rinsing the tubes with sterile PBS $(500 \mu \mathrm{l})$. Adult thrips fed on PBS-inoculated peanut leaflets and processed similarly for feces collection served as a negative control. Salivary secretions in sucrose solution were collected by rinsing the lower Parafilm layer with sterile PBS $(200 \mu \mathrm{l})$. For the pathogenicity test on onion, $0.1 \mathrm{ml}$ of the rinsed buffer from each subset was placed at the cut end of an onion leaf. Onion seedlings were scored and center rot incidence (percent) was recorded at 6 to 12 days postinoculation (DPI). Onion leaves mechanically inoculated with $P$. ananatis at $1 \times$ $10^{6} \mathrm{CFU} / \mathrm{ml}$ as described above served as a positive control. Additionally, the presence of $P$. ananatis in fecal rinsates was confirmed by spread plating $0.1 \mathrm{ml}$ of rinsate from each thrips subset on PA-20 agar plates. The presence of bacterial colonies was determined after 6 days of incubation at $28^{\circ} \mathrm{C}$. In all, 10 replicates were used in a single experiment and the experiment was repeated one more time (20 replicates in total). Furthermore, to ascertain the presence of $P$. ananatis in thrips saliva, sucrose solution containing salivary secretions trapped between the two paraffin layers was collected and processed as described above. This experiment was also repeated one more time (20 replicates in total).

Confirmation of center rot of onion symptomatic seedlings. Bacterial isolations were performed to confirm that the symptoms observed on seedlings were caused by $P$. ananatis. Small pieces $\left(2 \mathrm{~mm}^{2}\right)$ of tissue bordering the symptomatic and asymptomatic areas from 10 seedlings per experiment were macerated using a sterile scalpel with a number 3 blade (DR Instruments) in $20 \mu \mathrm{l}$ of $0.1 \mathrm{M}$ PBS. Tissue macerates were streaked onto both PA-20 and tryptic soy broth agar plates and incubated at $28^{\circ} \mathrm{C}$. After incubation, bacterial colonies were characterized based on morphology, gram reaction, oxidative and fermentative utilization of glucose, indole reaction, and nitrate reductase test. Furthermore, $P$. ananatis colonies were confirmed by real-time PCR assays with species-specific primers (Walcott et al. 2002), as described above.

Confirmation of $P$. ananatis strain PNA 97-1 reisolated from $F$. fusca or seedlings with center rot symptoms by repetitive extragenic palindrome PCR. Bacterial colonies (isolated from F. fusca or seedlings with center rot symptoms) confirmed as $P$. ananatis by growth on PA-20 semiselective medium, physiological tests, and real-time PCR assay were reconfirmed as the same strain used for inoculation by repetitive extragenic palindrome (rep)-PCR. Bacterial strains were inoculated into $3 \mathrm{ml}$ of nutrient broth and incubated on a rotary shaker (Innova; New Brunswick Scientific Co.) at $250 \mathrm{rpm}$ for $18 \mathrm{~h}$. After incubation, cells were harvested by centrifugation at $6,000 \times \mathrm{g}$ (Allegra 25R; Beckman Coulter) for 5 min and DNA was extracted using the UltraClean Microbial DNA Kit (Mo Bio), according to the manufacturer's instructions. For rep-PCR, $2 \mu \mathrm{l}$ of bacterial DNA was amplified using $10 \mu \mathrm{M}$ BOXA1R primer (5'-CTA CGG CAA GGC GAC GCT GAC G-3') according to PCR conditions, as described previously (Versalonic et al. 1994). PCR products $(10 \mu \mathrm{l})$ were separated by electrophoresis at $125 \mathrm{~V}$ for $4 \mathrm{~h}$ on a $1.5 \%$ agarose gel in $1 \times$ Tris-borate EDTA buffer. For comparison, rep-PCR was also conducted on DNA extracted from $P$. ananatis strain PNA 97-1, which was used as a reference bacterial strain. The DNA fingerprinting pattern of a reference strain was compared with the patterns obtained for the isolated strains (thrips and symptomatic seedlings).

\section{RESULTS}

Surface sterilization of peanut leaflets and $\boldsymbol{F}$. fusca larvae and adults. $P$. ananatis colonies were not isolated from the rinsates of surface-disinfested and noninfected peanut leaflets on PA-20 agar plates. Additionally, bacterial colonies were also not recovered from $F$. fusca rinsates (from the last rinsing step with PBS) postsurface sterilization.

Acquisition of $P$. ananatis by $F$. fusca adults and larvae. F. fusca larvae and adults did not acquire $P$. ananatis after a 48-h AAP from PBS-treated peanut leaflets. In contrast, $F$. fusca adults 
and larvae acquired $P$. ananatis following acquisition access on treated leaflets. $P$. ananatis acquisition percentages in $F$. fusca adults after 1- and 6-h AAP were 7.1 and $28.5 \%$, respectively (Fig. 1A). The mean percentages of $P$. ananatis acquisition by larvae after 1- and 6-h AAP were 4.2 and 25\%, respectively (Fig. 1B). At a 24-h AAP, 47.6 and $45.8 \%$ of the adults and larvae, respectively, were positive for $P$. ananatis. Acquisition percentages did not vary with experiments in adults $\left(d f=4,115, \chi^{2}=2.55, P=0.77\right)$ and larvae $\left(d f=4,115, \chi^{2}=2.23, P=0.82\right)$. Data from experiments were combined and subjected to regression analysis. Results showed an exponentially positive relationship between AAP and percentages of adult $F$. fusca acquiring $P$. ananatis $\left(R^{2}=0.79, P<0.01\right)$, with $73.8 \%$ of adults acquiring the bacterium after a 48 -h AAP (Fig. 1A). An exponentially positive relationship also was observed between AAP and percentages of $F$. fusca larvae acquiring $P$. ananatis $\left(R^{2}=\right.$ $0.77, P<0.01$ ), with $70.8 \%$ of larvae acquiring the bacterium (Fig. 1B) after a 48-h AAP.

Transstadial persistence of $\boldsymbol{P}$. ananatis in $\boldsymbol{F}$. fusca. $P$. ananatis colonies were not recovered from $F$. fusca samples exposed to PBStreated leaflets. The mean percentages of larvae ( $6 \mathrm{~h}$ postexposure) and pupae ( $96 \mathrm{~h}$ postexposure) that tested positive for $P$. ananatis were 51.2 and $50 \%$, respectively. In contrast, at the adult stage (144 $\mathrm{h}$ postexposure), the percentage of positive samples was approximately six times less $(8.3 \%)$ than in the other two stages. In this experiment, following AAP, thrips were reared on surfacedisinfested leaflets changed on alternate days. Also, F. fusca pupae are not mobile and do not feed. Therefore, presence of $P$. ananatis in the adults following molting from the pupal stages confirmed that $P$. ananatis persisted in thrips transstadially.

Effect of $\boldsymbol{P}$. ananatis acquisition on $\boldsymbol{F}$. fusca fitness. Thrips were monitored for an entire generation (adult to adult) in Munger cages on peanut leaflets with and without epiphytic populations of $P$. ananatis. The number of adults developed per adult released did not vary with the repeats of the experiment $(d f=2,27, F=1.74$, $P=0.19)$. Also, no differences between treatments were noticed ( $d f=1,28, F=1.74, P=0.74)$. These results indicated that the presence of epiphytic populations of $P$. ananatis had no effect on thrips development. The median developmental time to complete one generation (adult to adult) on leaves with and without P. ananatis populations were 15 days (12 to 19) and 15 days (14 to 18), respectively. Numbers in parentheses represent ranges in first adult development time in individual Munger cells. Developmental time of $F$. fusca was not influenced by the presence of $P$. ananatis $(d f=1.22, Z=1.39, \operatorname{Pr}>|Z|=0.16)$.

Immunolocalization of $P$. ananatis in $F$. fusca adults. The toluidine-blue-stained section showed anatomical features of F. fusca (Fig. 2A and C). Sections of negative controls ( $F$. fusca on PBS-treated peanut leaflets) that were labeled with antirabbit immunoglobulin G conjugated with Alexa-fluor 488 alone did not produce fluorescent signals (Fig. 2B). This indicated the absence of nonspecific binding of the secondary antibody to thrips tissues (Fig. $2 B$ ). When the sections of $F$. fusca were immunolabeled with primary and secondary antibodies and observed under a fluorescent microscope, immunolabeling of $P$. ananatis was visible in the esophagus, midgut 1 , midgut 2 , midgut 3 , and hindgut (Fig. 2D). $P$. ananatis was not observed in any other tissues within thrips or on thrips cuticle. Immunolabeled sections from all 10 thrips indicated that $P$. ananatis was exclusively localized in the gut.

Transmission of $P$. ananatis to onion seedlings through F. fusca salivary and fecal rinsates obtained through membrane feeding. $P$. ananatis colonies were not recovered from sucrose solution trapped between paraffin film layers by plating on PA-20 medium, suggesting that the bacterium was absent in salivary secretions. In contrast, $P$. ananatis colonies were recovered from $100 \%$ of the fecal rinsates that were exposed to the bacterium. In two independent experiments, $45 \%$ (average) of the onion seedlings that were inoculated with thrips fecal rinsates developed center rot symptoms by $12 \mathrm{DPI}$. Of the seedlings that were mechanically inoculated with $P$. ananatis as a positive control, $100 \%$ displayed typical center rot symptoms at 6 DPI.

Leaf tissues from seedlings that displayed center rot symptoms were used for bacterial isolation. Bacterial isolates were further tested for P. ananatis. Target bacterial colonies were isolated from $100 \%$ of the symptomatic seedlings. The isolated colonies were observed as small (3 to $4 \mathrm{~mm}$ in diameter), yellow-colored, shiny colonies with dark yellow granules at the center, on PA-20 semiselective medium. Further testing of colonies revealed that they were gram negative, could utilize glucose as a facultative anaerobe, and were positive for indole and negative for nitrate reductase tests. Amplification of DNA from three random colonies per plate by $P$. ananatis-specific realtime PCR primers confirmed the identity of the bacterium. Seedlings inoculated with sucrose solution remained asymptomatic.
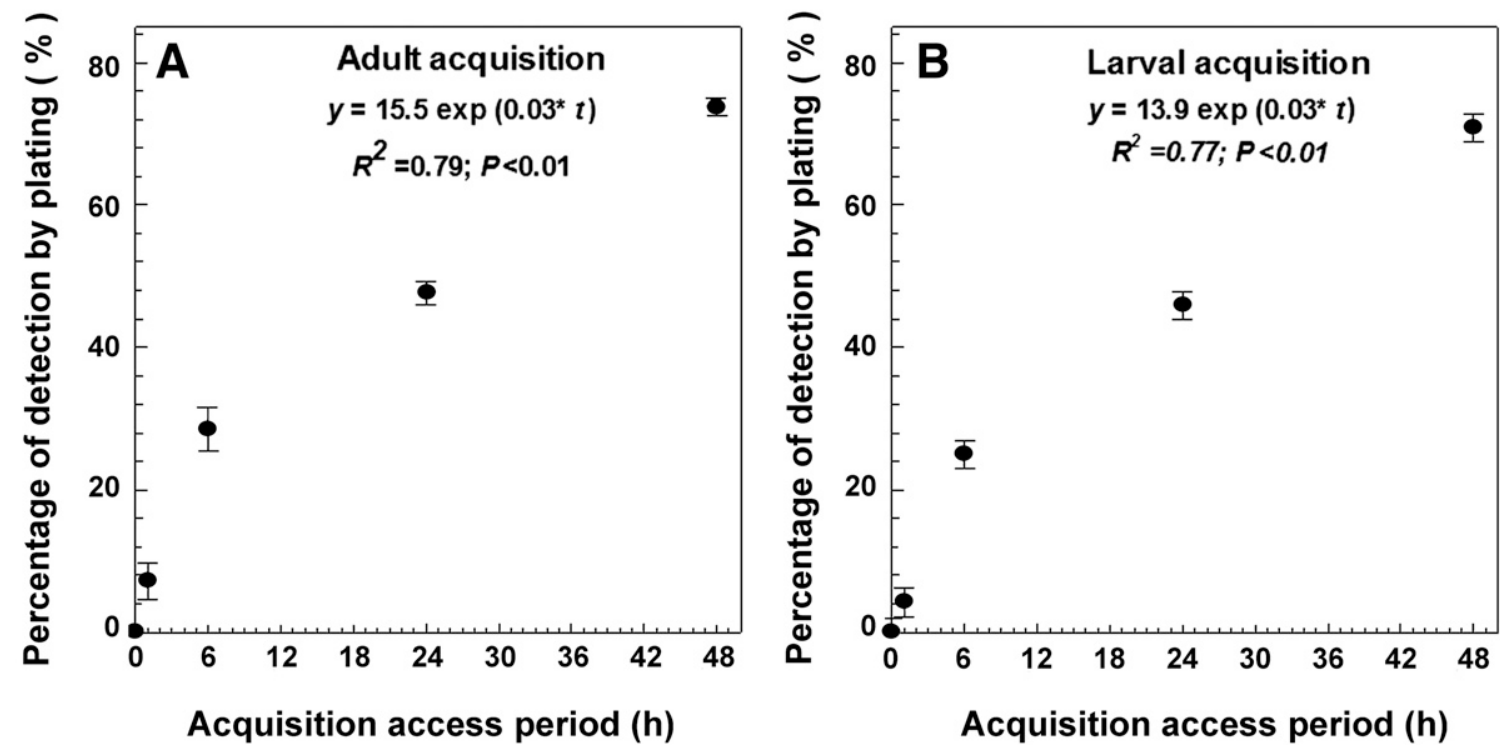

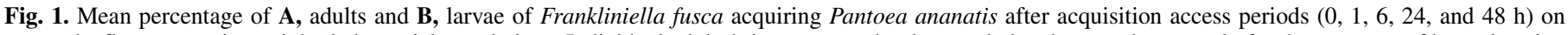

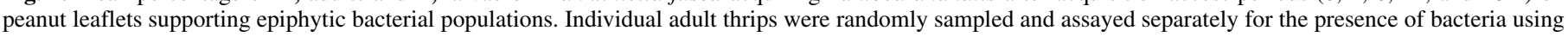

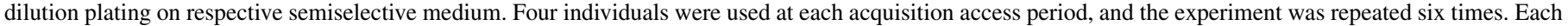
data point represents the mean of six experiments and the error bars represent standard error for the mean. 
Confirmation of $P$. ananatis strain PNA 97-1 reisolated from $F$. fusca or seedlings with center rot symptoms by repetitive extragenic palindrome (rep)-PCR. DNA fingerprinting patterns obtained by rep-PCR of bacterial strains isolated from thrips or center rot infected seedlings were identical to known pattern of a P. ananatis reference strain (PNA 97-1) (Fig. 3).

\section{DISCUSSION}

Prior to this study, it was not clear how acquisition of a phytopathogenic bacterium varied with life stages of its thrips vector, and how long the acquired bacterium persisted in thrips. Results from this study revealed that both adults and larvae of $F$. fusca could efficiently acquire $P$. ananatis from a contaminated food source. Once acquired, the bacterium persisted transstadially in F. fusca. Despite the acquisition and persistence in the insect, there seems to be no noticeable effects on thrips fecundity (adults recovered per adult released) and developmental time. Additionally, immunolabeled microscopy revealed that $P$. ananatis was only localized in the gut of $F$. fusca and nowhere else in the insect body. These results suggest that the bacterium is not circulative in the insect. Absence of $P$. ananatis infection in onion seedlings following mechanical inoculation of sucrose solution potentially containing salivary secretions indicated that the bacterium was not transmitted through saliva. Furthermore, infection of $P$. ananatis on onion seedlings following mechanical inoculation of fecal rinsates suggested that the bacterium was likely transmitted to onion seedlings via feces.
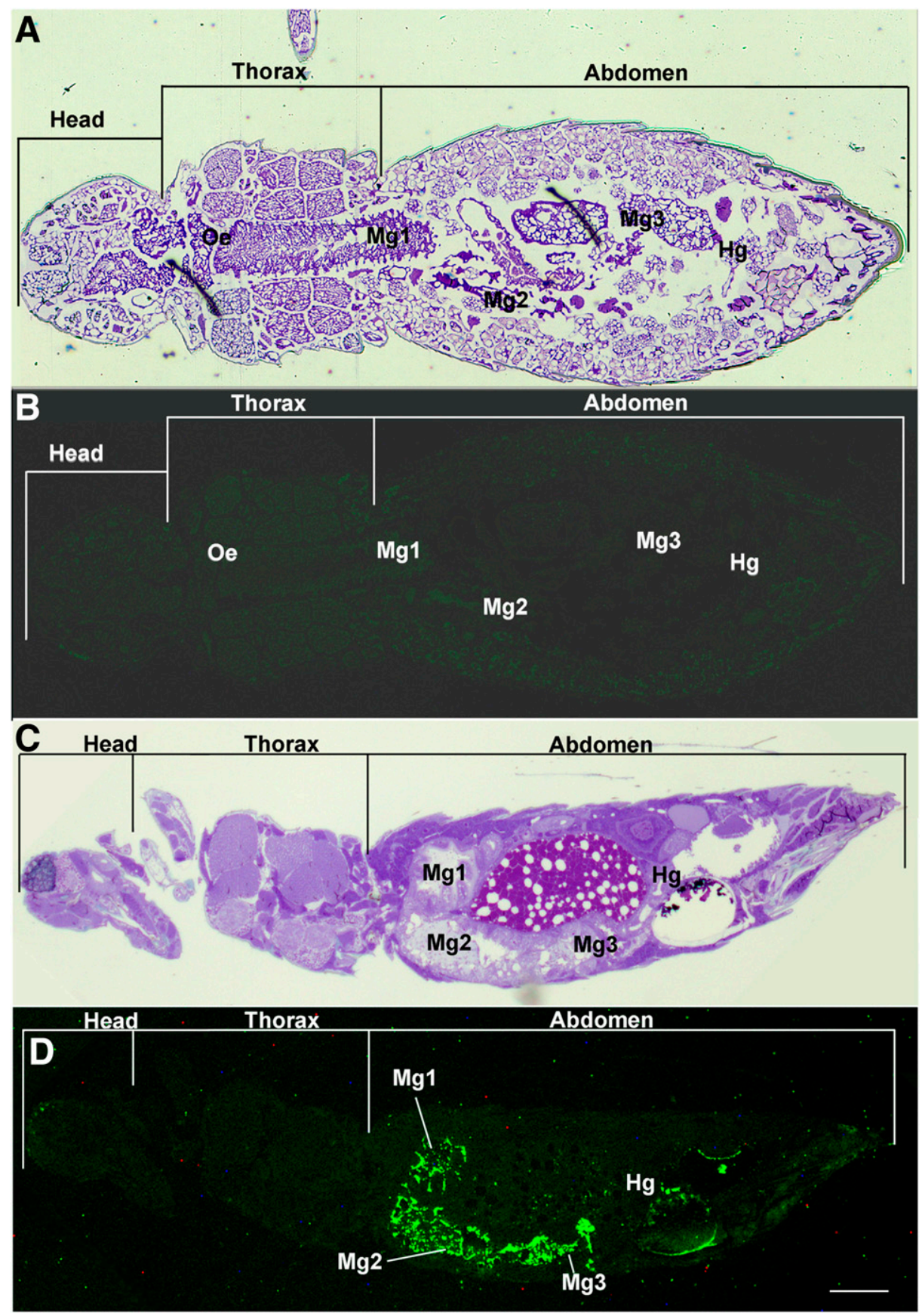

Fig. 2. Immunolocalization of Pantoea ananatis in adult Frankliniella fusca. A, Micrograph of negative control $F$. fusca stained with toluidine blue dye; B, immunolabeled micrographs of negative control F. fusca; $\mathbf{C}, F$. fusca micrograph stained with toluidine blue dye that fed on epiphytic populations of $P$. ananatis; D, immunolabeled micrograph of $F$. fusca fed on epiphytic populations of $P$. ananatis. $\mathrm{TH}=$ thorax; Oe $=$ esophagus; $\mathrm{MG}=$ midgut 1,2 , and 3 ; and $\mathrm{HG}=$ hindgut. Fluorescing green areas show the localization of $P$. ananatis cells in the gut of $F$. fusca. Bars correspond to $100 \mu \mathrm{m}$. 
P. ananatis was found in surface-sterilized larvae and adults of $F$. fusca following acquisition access on contaminated peanut leaflets. Both life stages acquired $P$. ananatis within $1 \mathrm{~h}$ of AAP and, by $48 \mathrm{~h}$ of AAP, approximately $70 \%$ of the thrips tested acquired the bacterium. In addition, there was a strong linear relationship between AAP and $P$. ananatis acquisition from a contaminated food source. Longer acquisition periods exponentially increased the probability of $P$. ananatis acquisition by $F$. fusca larvae and adults. Similar observations were made in the case of another phytopathogenic bacterium (X. fastidiosa) and the blue green sharpshooter (Graphocephala atropunctata Signoret), where a minimum AAP of $2 \mathrm{~h}$ was required for the vectors to become infective (Purcell and Finlay 1979). Other experiments demonstrated that an increase in AAP up to $12 \mathrm{~h}$ led to increase in X. fastidiosa transmission by $68 \%$ of the adults (Hill and Purcell 1995). Daugherty and Almeida (2009) observed that the acquisition efficiency of $X$. fastidios $a$ by glassywinged sharpshooter (Homalodisca vitripennis Germar) was dependent on pathogen populations in infected plants and lengths of AAP. It is not clear whether $P$. ananatis acquisition is dependent upon epiphytic pathogen densities because the experiments were conducted using high densities of $P$. ananatis $\left(1 \times 10^{6} \mathrm{CFU} / \mathrm{ml}\right)$; however, it is likely that the acquisition of $P$. ananatis by $F$. fusca would also be density dependent.

Even though $P$. ananatis persisted through the different life stages of $F$. fusca, the infection percentages decreased with time. The infection percentages in surface-sterilized larvae and pupae were more or less similar (approximately $50 \%$ ) but were substantially (six times) less in adults. The loss of bacteria in adults could be due, in part, to the fact that thrips is a hemimetablolous insect, and anatomical reorganization from pupae to adults is more extensive than transitioning from larvae to pupae (Johnson and Triplehorn 2004; Tipping 2008). Persistence of Enterobacteriaceae members through vector life stages is also documented in other pathosystems. For instance, P. stewartii (Smith) persisted in the flea beetle Chaetocnema pulicularia (F. E. Melsheimer) for its life, upon

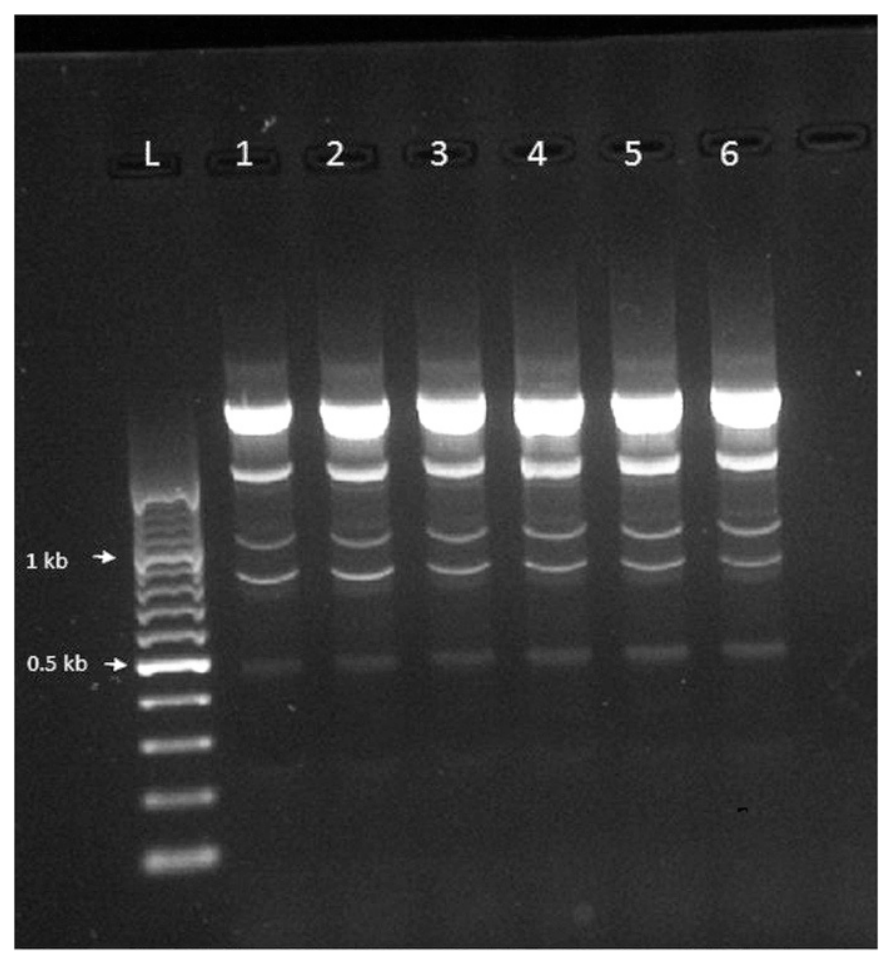

Fig. 3. DNA fingerprinting pattern of Pantoea ananatis strains reisolated from symptomatic onion seedlings and thrips (after acquisition and persistence experiments) using repetitive extragenic palindrome polymerase chain reaction. Lanes in the gel image denote the following: lane $\mathrm{L}=100$-bp ladder (New England Biolabs), lane 1 = PNA 97-1 (reference strain), lanes 2 to $4=$ $P$. ananatis reisolated from symptomatic onion seedlings, and lanes 5 and $6=$ $P$. ananatis reisolated after acquisition and persistence experiments. acquisition at the larval stage (Esker and Nutter 2003; Menelas et al. 2006).

Fitness experiments indicated that the persistence of the bacterium had no effect on the fecundity (adults recovered per adult released) of thrips as well as on thrips developmental time. These results indicated that persistence of the bacterium had no beneficial or deleterious fitness effects on thrips themselves. These findings were contrary to observations made by de Vries et al. (2004). Their study identified positive fitness effects in the case of the western flower thrips, F. occidentalis (Pergande), with the gut bacterium Erwinia sp. when compared with thrips without the gut bacterium. Bacteria-laden thrips had a shorter larval development time and increased fecundity when compared with thrips without the enterobacterium (de Vries et al. 2001). Even though P. ananatis and Erwinia sp. found on F. occidentalis are taxonomically similar (members of Enterobacteriaceae), it is not clear why such fitness benefits were not observed with $F$. fusca.

Immunofluorescence microscopy further shed some light on bacteria localization in thrips and allowed us to identify the mechanism of transmission. Immunofluorescence micrographs of adult $F$. fusca with a 48-h AAP on $P$. ananatis-infected leaflets indicated that the bacterium was localized only in the gut. The absence of immunofluorescence on the outer cuticle further reiterated that there was no contamination and that surface sterilization was effective. The absence of $P$. ananatis in other insect tissues such as salivary glands suggested that the pathogen is not circulative. These results are similar to what was observed with onion thrips, $T$. tabaci and $P$. ananatis (Dutta et al. 2014). This observation was not surprising because $P$. ananatis is a member of Enterobacteriaceae, which includes several gut-residing bacteria such as Erwinia and Pectobacterium spp. in thrips and other insects (de Vries et al. 2001).

$P$. ananatis populations were not associated with mouth parts of F. fusca, thereby suggesting that the bacterium might not be transmitted through thrips feeding. Membrane-based feeding assays showed that $P$. ananatis might be transmitted via feces and not by salivary secretions. Together, our findings suggest that the pathogen could infect onion through the feeding injuries and simultaneous fecal contamination. These results were in line with our earlier findings, which documented $P$. ananatis transmission by T. tabaci through feces (Dutta et al. 2014). The transmission of $P$. ananatis by $T$. tabaci and $F$. fusca through feces suggests that mode of transmission is similar among thrips vectors.

Though our previous research also indicated that $T$. tabaci could transmit $P$. ananatis via feces (Dutta et al. 2014), the findings in this study include information on acquisition and persistence of $P$. ananatis in various life stages of thrips, and also on thrips fecundity and development. Prior to this study, such information pertaining to transmission of plant-pathogenic Enterobacteriaceae members by thrips was lacking. In addition, the findings in this manuscript validate our previous findings on the mode of $P$. ananatis transmission by thrips (Dutta et al. 2014), and suggest that the mode of $P$. ananatis transmission via feces (setrcorarion transmission) is conserved among vector thrips species.

\section{ACKNOWLEDGMENTS}

We thank D. Ullman, Professor (Entomology) at the University of California, Davis for her helpful critique of the manuscript; and S. Smith, K. Parris, and E. Holliman for their technical assistance.

\section{LITERATURE CITED}

Almeida, R. P. P., Winstrom, C., Hill, B. L., Hashim, J., and Purcell, A. H. 2005. Vector transmission of Xylella fastidiosa to dormant grape. Plant Dis. 89:419-424.

Bell, A. A., Medrano, E. G., Lopez, J. D., and Luff, R. K. 2007. Transmission and importance of Pantoea ananatis during feeding on cotton buds (Gossypium hirsutum L.) by cotton fleahoppers (Pseudatomoscelis seriatus Reuter). In: Proc. World Cotton Res. Conf. Lubbock, TX. 
Bruton, B. D., Mitchell, F., Fletcher, J., Pair, S. D., Wayadande, A., Melcher, U., Brady, J., Bextine, B., and Popham, T. W. 2003. Serratia marcescens, a phloem-colonizing, squash bug transmitted bacterium: Causal agent of cucurbit yellow vine disease. Plant Dis. 87:937-944.

Daugherty, M. P., and Almeida, R. P. P. 2009. Estimating Xylella fastidiosa transmission parameters: Decoupling sharpshooter number and feeding period. Entomol. Exp. Appl. 132:84-92.

de Vries, E. J., Breeuwer, J. A. J., Jacobs, G., and Mollema, C. 2001. The association of western flower thrips, Frankliniella occidentalis, with a near Erwinia species gut bacteria: Transient or permanent? J. Invertebr. Pathol. 77:120-128.

de Vries, E. J., Jacobs, G., Breeuwer, J. A. J., Sabelis, M. W., and Menken, S. B. J. 2004. Diet dependent fitness effects of gut bacteria on their insect host: The symbiosis of Erwinia sp. and western flower thrips. Proc. R. Soc. Lond. B 271:2171-2178.

Diffe, S., Edwards, G. B., and Mound, L. A. 2008. Thysanoptera of southeastern U.S.A.: A checklist for Florida and Georgia. Zootaxa 1787:45-62.

Dutta, B., Barman, A. K., Srinivasan, R., Avci, U., Ullman, D. E., Langston, D. B., and Gitaitis, R. D. 2014. Transmission of Pantoea ananatis and Pantoea agglomerans, causal agents of center rot of onion (Allium cepa L.), by onion thrips (Thrips tabaci Lindeman) through feces. Phytopathology 104:812-819.

Esker, P. D., and Nutter, F. W. 2003. Temporal dynamics of corn flea beetle populations infested with Pantoea stewartii, causal agent of Stewart's disease of corn. Phytopathology 93:210-218.

Gitaitis, R., Walcott, R., Culpepper, S., Sanders, H., Zolobowska, L., and Langston, D. 2002. Recovery of Pantoea ananatis, causal agent of center rot of onion, from weeds and crops in Georgia, USA. Crop Prot. 21:983-989.

Gitaitis, R. D., and Gay, J. D. 1997. First report of a leaf blight, seed stalk rot, and bulb decay of onion by Pantoea ananas in Georgia. Plant Dis. 81:1096.

Gitaitis, R. D., Walcott, R. R., Wells, M. L., Diaz Perez, J. C., and Sanders, F. H. 2003. Transmission of Pantoea ananatis, causal agent of center rot of onion, by tobacco thrips, Frankliniella fusca. Plant Dis. 87:675-678.

Goszczynska, T., Venter, S. N., and Coutinho, T. A. 2006. PA-20, a semiselective medium for isolation and enumeration of Pantoea ananatis. J. Microbiol. Methods 64:225-231.

Hill, B. L., and Purcell, A. H. 1995. Acquisition and retention of Xylella fastidiosa by an efficient vector, Graphocephala atropunctata. Phytopathology 85:209-212.

Jarrett, C. O., Deak, E., Isherwood, K. E., Oyston, P. C., Fischer, E. R., Whitney, A. R., Kobayashi, S. D., DeLeo, F. R., and Hinnebusch, B. J. 2004. Transmission of Yersinia pestis from an infectious biofilm in the flea vector. J. Infect. Dis. 190:782-792.
Johnson, N. F., and Triplehorn, C. A. 2004. Order Thysanoptera: Thrips. Pages 327-342 in: Introduction to the Study of Insects. D. J. Borrer, C. A. Triplehorn, and N. F. Johnson, eds. Cengage Learning, Inc., Independence, KY

Mauck, K., Bosque-Pérez, N. A., Eigenbrode, S. D., Moraes, C. M., and Mescher, M. C. 2012. Transmission mechanisms shape pathogen effects on host-vector interactions: Evidence from plant viruses. Funct. Ecol. 26: 1162-1175.

Medrano, E. G., and Bell, A. A. 2007. Role of Pantoea agglomerans in opportunistic bacterial seed and boll rot of cotton (Gossypium hirsutum) grown in the field. J. Appl. Microbiol. 102:134-143.

Menelas, B., Block, C. C., Esker, P. D., and Nutter, F. W. 2006. Quantifying the feeding periods required by corn flea beetles to acquire and transmit Pantoea stewartii. Plant Dis. 90:319-324.

Mitchell, R. F., and Hanks, L. M. 2009. Insect frass as a pathway for transmission of bacterial wilt of cucurbits. Environ. Entomol. 38:395-403.

Munger, F. 1942. A method of rearing citrus thrips in the laboratory. J. Econ. Entomol. 35:373-375.

Nachappa, P., Shapiro, A. A., and Tamborindeguy, C. 2012. Effect of 'Candidatus Liberibacter solanacearum' on fitness of its insect vector, Bactericera cockerelli (Hemiptera: Triozidae), on tomato. Phytopathology 102: 41-46.

Purcell, A. H., and Finlay, A. H. 1979. Evidence of non-circulative transmission of Pierce's disease bacterium by sharpshooter leafhoppers. Phytopathology 69:393-395.

Schwartz, H. F., and Otto, K. 2000. First report of a leaf blight and bulb decay of onion by Pantoea ananatis in Colorado. Plant Dis. 84:808.

Sparks, A. N., Diffe, S., and Riley, D. G. 2011. Thrips species composition shift on onions in the Vidalia region of Georgia. J. Environ. Sci. (China) 46: 40-45.

Tipping, C. 2008. Thrips (Thysanoptera). Pages 3769-3771 in: Encyclopedia of Entomology. J. L. Capinera, ed. Springer, New York.

Versalonic, J., Schneider, M., de Bruijin, F. J., and Lupski, J. R. 1994. Genomic fingerprinting of bacteria using repetitive sequence-based polymerase chain reaction. Methods Mol. Cell. Biol. 5:25-40.

Walcott, R. R., Gitaitis, R. D., Castro, A. C., Sanders, F. H., Jr., and Diaz-Perez, J. C. 2002. Natural infestation of onion seed by Pantoea ananatis, causal agent of center rot. Plant Dis. 86:106-111.

Wells, M. L., Gitaitis, R. D., and Sanders, F. H. 2002. The Association of tobacco thrips. Frankliniella fusca, (Thysanoptera: Thripidae) with two species of bacteria of the genus Pantoea. Ann. Entomol. Soc. Am. 95: 719-723. 